\author{
FONSECA, Rodrigo Oliveira (Org.). A \\ Conjuração Baiana e os desafios da \\ igualdade no Brasil. São Carlos, SP: Pedro \\ \& João Editores, 2016. 238p.
}

\title{
GESTOS DE LEITURA EM DISCURSO E HISTÓRIA: DOS CAMINHOS PARA A IGUALDADE NA SOCIEDADE BRASILEIRA
}

\author{
JUCIELE PEREIRA DIAS ${ }^{1}$
}

Programa de Pós-Graduação em Ciências da Linguagem Universidade do Vale do Sapucaí

Av. Pref. Tuany Toledo, 470 - 37550-000 - Pouso Alegre - MG - Brasil

\section{RAPHAEL DE MORAIS TRAJANO}

\author{
Faculdade de Letras - Fundação Técnico-Educacional Souza Marques \\ Rio de Janeiro - RJ - Brasil \\ jucieledias@gmail.com, raphademorais@gmail.com
}

Pois produzir, é grande novidade:

Do jardim frutos, e das flores vida, Das sombras luzes, e da Pena glórias. (Manuel de Andrade de Figueiredo, 1722)

A Conjuração Baiana e os desafios da igualdade no Brasil é uma obra organizada pelo analista de discurso e historiador Rodrigo Oliveira Fonseca, da Universidade Federal do Sul da Bahia (UFSB), que em suas pesquisas coloca em cena discussões sobre os desafios da igualdade no Brasil e as maneiras como são produzidas leituras sobre o movimento revolucionário de 1798, a Conjuração Baiana. Ambas temáticas foram norteadoras de um projeto de pós-doutorado, pelo qual se inscrevem problematizações teóricas sobre as relações entre Discurso e História nos processos de produção dos conhecimentos. Tais discussões constituem os sete capítulos de pesquisadores de

\footnotetext{
${ }^{1}$ Doutora em Letras pela UFSM; professora no Programa de Pós-Graduação em Ciências da Linguagem da UNIVÁS. http://lattes.cnpq.br/6079679042863199.

2 Doutor em estudos da Linguagem pela UFF; professor na Faculdade de Letras da Fundação TécnicoEducacional Souza Marques. http://lattes.cnpq.br/2958155692837549.
} 
diferentes universidades brasileiras ${ }^{3}$, que, por diferentes campos do saber, estilhaçam a univocidade dos sentidos cristalizados na nossa história e dão condições ao leitor de (se) inscrever (n)a produção de outros sentidos na atualidade.

Composta de capítulos distribuídos em três partes - I) O movimento revolucionário baiano de 1798; II) Escravidão e Igualdade e III) História e Discurso -, a obra é aberta pelas as ousadas palavras de Phellipe Marcel da Silva Esteves (p. 9-14), analista de discurso, da Universidade do Estado do Rio de Janeiro (UERJ), ao nos convidar a trilhar a história por outros caminhos, considerando que "a interpretação é histórica" e que "a história já está clara o suficiente. Ela precisa de outras cores, outros sentidos, outras compreensões". O prefaciador - que se desloca do mero lugar de apresentar texto a texto - instiga o leitor a uma reflexão crítica sobre os movimentos sociais da história, na atualidade, com seus diferentes funcionamentos na (des)agregação das camadas populares, da Conjuração Baiana aos "discursos revolucionários provenientes da Europa, do Haiti, da América do Norte". Há de se salientar, nessa abertura, uma problematização dos inquietantes sentidos postos como "claros", evidentes hoje, a exemplo das concepções de "trabalho (e não de dever, obrigação, a própria natureza do escravizado)", de "ócio" e de outras práticas como a "capoeira" em uma sociedade determinada, estruturalmente, pela memória da escravidão.

A Primeira Parte - O movimento revolucionário baiano de 1798 - conta com três capítulos e é primorosamente iniciada por Rodrigo Oliveira Fonseca (p. 17-54), com o trabalho intitulado "Do impossível ao incontornável: a propósito das lições igualitárias deixadas pelos deslocamentos da Conjuração Baiana", que analisa a discursividade dos cartazes revolucionários de 1798 e também o modo como esse movimento se inscreve produzindo diferentes efeitos no discurso de historiadores. No ritmo de suas palavras, por seus ritournelles históricos, Fonseca faz bordas ao real histórico do movimento baiano do final do século XIX e toca a "dimensão do "impossível'” de um processo atravessado por "desigualdades", "incompletudes", "lacunas", "contradições" e por sentidos que emergem desse espaço virtual da história brasileira defrontando/(en)cantando o leitor com o inesperado que demanda por interpretação. Tocando na possibilidade de "uma apropriação politicamente produtiva e equívoca das ideias revolucionárias francesas", salienta o autor ter sido esse deslocamento que "permitiu a um conjunto de sujeitos estruturalmente deslocados trabalharem o impossível do igualitarismo republicano em uma ordem escravista colonial". A compreensão das condições de produção dos sentidos de "cativo", de "liberto", de "mulato", de "negro", bem como das relações sociais e, por sua vez, das relações de produção no sistema escravista colonial constituem-se como uma intervenção nos processos de produção dos conhecimentos sobre "essa difícil e complexa construção cotidiana da liberdade (ou de liberdades), tanto para os cativos quanto para os libertos" na história, em sua atualidade. Trata-se de um trabalho de fôlego e denso que necessariamente coloca em cena o "elemento antirracista", destacado nos "papéis incendiários" (cartazes de 1798) enquanto uma subjetividade daquele movimento e que o inscreve, historicamente, na "era das revoluções" do século XIX.

${ }^{3}$ UERJ, UFSB, UNEB, UCSal, UNICAMP, UESB, UFRGS, UPF, UFRPE. 
Em nossos percursos pela leitura, temos o segundo capítulo "O dever de defender e o querer condenar: contribuição da Filologia e da Análise do Discurso à compreensão da defesa dos réus na Conspiração de 1798", produzido pelo filólogo João Antonio de Santana Neto (p. 55-75), da Universidade do Estado da Bahia (UNEB), que potencializa a obra ao encaminhar a discussão sobre o acontecimento de 1798 para o campo da Filologia posto em relação com a Análise de Discurso e a História. Com fluidez didática, são definidas as noções de Filologia e da Análise de Discurso como uma via para a introdução do precioso corpus de análise constituído por recortes da conclusão da 'Defesa dos Reos", presente nos Autos da Devassa da Conspiração dos Alfaiates, de 17981799. Vale destacar as maneiras de ler do autor ao colocar em cena a questão do poder político ser determinado por "imperativos divinos" ou por um "soberano absoluto", que, por sua vez, posicionava-se "a partir dos valores morais e religiosos então dominantes". No processo de análise, são mobilizadas as imagens que o "defensor" faz dos "réus" ("miseráveis", "infelizes"), bem como as imagens que o "defensor" faz de si mesmo e de seu trabalho ("débil defensor", "vassalo" da "Rainha Nossa Senhora", "obrigação") sob a proteção e intercessão da "Rainha Nossa Senhora" em relação ao "Deus", o "Juiz celeste".

$\mathrm{Na}$ sequência da obra, alinhavando um fechamento da primeira parte temática, temos o surpreendente capítulo intitulado "Conspiração dos Alfaiates: Liberdade. Que liberdade?", de autoria da historiadora Maria Helena Ochi Flexor (p. 77-118), da Universidade Católica de Salvador (UCSal), a qual nos oferta um arquivo inestimável construído pelas leituras de dez transcrições de "pasquins ou pesquins", produzidas tanto sob o rigor científico de um olhar semântico quanto filológico. Pela análise das "letras e conceitos" de grande parte desses documentos do século XVIII, Flexor observa serem materiais de "caligrafias muito semelhantes, diferenciando-se apenas no tamanho das letras". Isso a leva a colocar as referidas produções em relação a obra de Manuel de Andrade de Figueiredo, intitulada Nova Escola para aprender a ler, escrever, e contar, de 1722, que teria sido um instrumento linguístico normalizador tanto nas instituições públicas, quanto nas escolas, com ampla circulação. A referência a este caligrafo, poeta e educador, conciliador de ideias humanísticos e religiosos nas Artes liberais, abre as portas para o imaginário sobre a ornamentação e o potencial poético dos discursos sobre esses papéis revolucionários que mobilizou o povo baiano em prol da liberdade, igualdade e fraternidade. Este texto de Flexor, fundamentado no saber filológico, na relação com outros textos essa obra, dá condições para a emergência de outros sentidos sobre os discursos produzidos no movimento revolucionário de 1798.

A Segunda Parte - Escravidão e Igualdade - conta com dois capítulos e é brilhantemente iniciada por Eduardo Guimarães (p. 123-144), da Universidade Estadual de Campinas (UNICAMP), com o trabalho intitulado "A não igualdade dos não ingênuos: sobre escravos e cidadãos no século XIX no Brasil". Produzindo a entrada pela reflexão acerca dos sentidos de cidadão e de escravo no Brasil do século XIX, o autor, de maneira estimulante, propõe assunção do posicionamento de quem não pretende tão-somente contar a história de cidadãos e escravos, tampouco narrar e descrever aspectos inerentes à história do Brasil. Assim, o que ousa oferecer em seu texto é uma abordagem imperiosa, nos termos em que nos orienta, de modo singular, a percorrer a história de cidadãos e escravos por meio dos sentidos. Ousa seja, a transitar por esta história tendo como ponto 
de partida o modo como tais sujeitos são historicamente significados no Brasil. No efeito de fechamento de um trabalho consequente, faz-nos pensar sobre a hipótese de que "o sentido de uma performatividade externa à cidadania que a estabiliza, se deslocou", em um gesto de abertura à continuidade da produção de questões que permitam avançar nas investigações. Mais um texto desses que surpreendem pela proposta de abandono do lugar-comum em termos de pesquisa e reflexão, a fim de apresentar um percurso pautado não naquilo que se compreende como "a história", mas no que nos é dado a ver em seu texto como a historicidade enquanto processo.

$\mathrm{Na}$ sequência, mais um belo empreendimento teórico-analítico, no qual Jorge Viana Santos (p. 145-170), do Departamento de Estudos Linguísticos e Literários (DELL) da Universidade Estadual do Sudoeste da Bahia (UESB), apresenta alguns desdobramentos de seu projeto de pós-doutorado realizado pela Unicamp (2013-2014). $\mathrm{O}$ autor inicia seu capítulo a partir de uma remontagem à história do trabalho, tomandoo, pois, como uma realidade pluridimensional, "seja do ponto de vista linguísticosemântico, seja do ponto de vista da realidade sócio-histórica”. Este é o ponto de partida para a construção de uma abordagem suntuosa, que investiga os sentidos de trabalho relacionados à liberdade no Brasil escravista (1830 a 1888) e os sentidos de trabalho relacionados à liberdade no Brasil pós-abolição (1889 a 1940), tomando como base teórico-metodológica a Semântica do Acontecimento (GUIMARÃES, 1995; 2002; 2011). Desse modo, constrói uma análise que explicita a forma como, nos textos analisados, são apontados "funcionamentos semânticos de 'trabalho' que se diferenciam, ampliam-se e se mantêm, conforme o período considerado". Muito mais do que o anunciado nesta crítica, o leitor poderá conferir em um texto que, pela relevância das problemáticas levantadas e pela maneira como são abordadas, tem potencial para tornarse referência necessária a inúmeros estudos que estabeleçam como temática a questão do 'trabalho'.

A Terceira Parte - História e Discurso - conta com dois capítulos e é aberta por Florence Carboni e Mário Maestri (p. 172-220), da Universidade Federal do Rio Grande do Sul (UFRGS) e da Universidade de Passo Fundo (UPF) respectivamente, com o capítulo intitulado "Signo e luta de classes: por uma epistemologia da representação no Brasil escravista". Um texto de fôlego admirável, sobretudo pelo modo como os autores textualizam uma abordagem de cunho linguístico e histórico acerca de representações no Brasil escravista. Nesse movimento, toma como ponto de entrada a discussão sobre o estranhamento provocado pela constatação, com base em Gorender (1979), de uma correspondência entre as representações e interpretações historiográficas voltadas ao trabalhador escravizado, além do status adquirido por este na escravidão brasileira: [...] "Paradoxo que contraditava com o papel social dominante do cativo, primeiro americano, depois negro-africano, até praticamente 1888 " (p. 174). Tamanha é a importância e indispensabilidade deste trabalho, que preferimos não ir além, nesta crítica, do lançamento de mais do que um aperitivo, a fim de que o leitor se sinta instigado a embarcar na proposta dos autores, constituída a partir de uma gama de referências que dotam a escrita de um volume epistemológico e intelectual impressionantes. 
Como fechamento da obra, temos o capítulo de Giselda Brito Silva, da Universidade Federal Rural de Pernambuco (UFRPE), intitulado "Na fronteira entre a História e a Análise do Discurso: diálogos necessários", em que o adjetivo "necessários" encena a urgência explicitada na demanda pelo estabelecimento de uma relação crucial que se constrói na fronteira entre dois distintos campos do saber: Análise do Discurso e História. Assim, entre importantes delimitações e demarcações, destaca-se o fato de muitos historiadores lançarem mão de conceitos e noções da Análise do Discurso, a qual, com seu objeto - o discurso -, trabalha na contramão de algumas concepções caras ao campo conceitual da História. Assim se configuram, portanto, as pretensões deste trabalho admirável, entre as quais a de permitir que "a História continue aproveitando as contribuições da Análise do Discurso (AD) e vice-versa", mesmo em meio a uma convivência epistemológica permeada de "embates e dificuldades", sobre as quais a autora propõe falar em um artigo de importância inquestionável para o conjunto da obra que integra.

Resenha recebida em: fevereiro de 2017.

Aprovada e revisada em: março de 2017.

Publicada em: abril de 2017.

\section{Para citar este texto:}

DIAS, Juciele Pereira; TRAJANO, Raphael de Morais. Gestos de leitura em discurso e história: dos caminhos para a igualdade na sociedade brasileira. Entremeios [Revista de Estudos do Discurso], Seção Resenha, Programa de Pós-graduação em Ciências da Linguagem (PPGCL), Universidade do Vale do Sapucaí, Pouso Alegre (MG), vol. 14, p. 321-325, jan. - jun. 2017. (Resenha de FONSECA, Rodrigo Oliveira (Org.). A Conjuração Baiana e os desafios da igualdade no Brasil. São Carlos, SP: Pedro \& João Editores, 2016. 238p.)

DOI: http://dx.doi.org/10.20337/ISSN2179-3514revistaENTREMEIOSvol14pagina321a325 